\title{
RECEITA TRIBUTÁRIA, EXTRAFISCALIDADE E INTERVENÇÃO NO DOMÍNIO ECONÔMICO
}

\subsection{ENTRADAS E RECEITAS - CONCEITO, DISTINÇÃO E CLASSIFICAÇÃO}

Conforme sublinhado, o Estado, para cumprir suas finalidades e com isso atender às necessidades estabelecidas na Constituição Federal, tem de auferir recursos, os quais, de acordo com Geraldo Ataliba, podem ser obtidos de duas maneiras: "auferindo lucros, na venda de bens e serviços, ou usando de seu poder para exigir o concurso compulsório das pessoas sujeitas a seu poder, para as necessidades públicas" ${ }^{286}$.

A propósito, Aliomar Baleeiro ${ }^{287}$ salienta que todos os processos de financiamento do Estado se enquadram, ou já se enquadraram historicamente, em um dos seguintes meios de obtenção de receita: (i) extorsão; (ii) recolhimento de rendas, produzidos pelos bens e empresas do Estado; (iii) exigência coativa de tributos e penalidades; (iv) tomada de empréstimos; e (v) fabricação de dinheiro metálico ou papel moeda.

Atualmente, o Estado brasileiro, para obter recursos necessários à satisfação de suas despesas, vale-se principalmente: (i) da cobrança de tributos; (ii) da exploração de seu patrimônio, a qual pode dar-se em decorrência do percebimento de valores provenientes de empresas estatais, com a comercialização de recursos minerais,

\footnotetext{
286 ATALIBA, Geraldo. Apontamentos das ciências das finanças, direito financeiro e tributário. São Paulo: RT, 1969. p. 25.

287 BALEEIRO, Aliomar. Uma introdução à ciência das finanças, p. 115.
} 
petrolíferos e energéticos, e em decorrência da concessão de bens públicos; e, ainda, (iii) da contração de empréstimos.

Daí, portanto, é que se diz genericamente que "receita é a soma de dinheiro percebida pelo Estado para fazer face à realização dos gastos públicos" 288 , ainda que nem toda receita possa assim ser considerada, pois esse conceito, como adverte Ricardo Lobo Torres, é "fundamentalmente baseado no de ingresso" e "dele se estrema, pois o ingresso corresponde também à entrada de dinheiro que ulteriormente será restituído"289.

Nessa linha também se manifestou Regis Fernandes de Oliveira ${ }^{290}$, ao afirmar que "nem todo ingresso, todavia, constitui receita. Há entradas que ingressam provisoriamente nos cofres públicos, podendo neles permanecer ou não. Destinam-se a ser devolvidas" 291 e, portanto, são denominadas entradas provisórias, como por exemplo, os empréstimos compulsórios.

A contrapor-se às entradas provisórias, há aquelas denominadas entradas definitivas, ou seja, "as que advêm do poder constritivo do Estado sobre o particular, sejam independentes de qualquer atuação (imposto), sejam dela dependentes (taxa) ou em decorrência da realização de obras públicas (contribuição de melhoria)"292.

Aliomar Baleeiro, levando em consideração os aspectos apontados, conceitua receita pública como "(...) a entrada que, integrando-se no patrimônio público sem que quaisquer reservas, condiçôes ou correspondência no passivo, vem acrescer o seu vulto, como elemento novo e positivo"293.

Pode-se assim dizer que receita pública é aquela que se destina a permanecer em definitivo nos cofres públicos, ou, como sublinha Regis Fernandes de Oliveira, "é a entrada definitiva de dinheiro e bens nos cofres públicos"294.

Como a entrada consiste em definitivo de dinheiro e bens nos cofres públicos, verifica-se que ela pode provir de diversas fontes ou formas de receita. E, com o propósito de empregar maior controle e transparência ao orçamento público, passou-se a proceder ao seu agrupamento por categorias e a estabelecer determinados modos de classificação que variam de acordo com a necessidade e o interesse de quem os estabelece.

\footnotetext{
288 TORRES, Ricardo Lobo. Curso de direito financeiro e tributário, p. 185.

289 TORRES, Ricardo Lobo. Curso de direito financeiro e tributário, p. 185.

290 OLIVEIRA, Regis Fernandes de. Curso de direito financeiro, p. 126-127.

291 OLIVEIRA, Regis Fernandes de. Curso de direito financeiro, p. 126.

292 OLIVEIRA, Regis Fernandes de. Curso de direito financeiro, p. 127.

293 BALEEIRO, Aliomar. Uma introdução à ciência das finanças, p. 116.

${ }^{294}$ OLIVEIRA, Regis Fernandes de, op. cit., p. 128.
} 
Para que se tenha uma ideia de sua amplitude, no âmbito Federal, o detalhamento da classificação da receita cabe à Secretaria de Orçamento Federal (SOF) e é feito por meio de portaria, na qual são estabelecidas as classificações orçamentárias de acordo com sua natureza e fonte de recursos ${ }^{295}$.

Em face da grande diversidade de classificaçóes, as quais, novamente, cumpre frisar, não são verdadeiras nem falsas, mas úteis ou inúteis, como ensina Genaro Carrióo ${ }^{296}$, será adotado um critério que se aproxime do objeto de estudo da presente dissertação e que se mostre útil, a fim de evitar classificações puramente abstratas e sem critério algum.

A classificação jurídica, nesse sentido, mostra-se a mais pertinente, por ser proveniente da análise do ordenamento normativo e, ao mesmo tempo, econômica, pois leva em conta a pessoa que desenvolve a atividade econômica que propicia a geração de riqueza convertida em receita.

Além do mais, essa classificação mostra-se relevante para o presente estudo na medida em que, e por meio dela, será possível identificar quais e onde se encontram alocadas as principais fontes de receita do Estado, bem como demonstrar dentre elas sua relevância para o domínio econômico, uma vez que é por meio delas que são desenvolvidas todas as atividades do Estado e praticados os atos de intervenção.

\subsubsection{Receitas ordinárias e extraordinárias}

De acordo com o critério da regularidade ou relativa periodicidade, as receitas públicas também se classificam em ordinárias e extraordinárias.

Em suma, as receitas ordinárias caracterizam-se por serem periódicas e por comporem permanentemente o orçamento do Estado, enquanto as receitas extraordinárias são as que se produzem excepcionalmente, como as doações e os impostos extraordinários ${ }^{297}$, ou seja, "receitas que, pelo seu caráter temporário, irregular e contingente, ou pelas circunstâncias eventuais e excepcionais de que se revestem, não se enquadram no rol dos ingressos permanentes e ordinários do Tesouro"298.

295 Veja-se BRASIL. Ministério do Planejamento, Orçamento e Gestão; Secretaria de Orçamento Federal. Ementário de receitas da Uniāo. Disponível em: <http://www.orcamentofederal. gov.br/informacoes-orcamentarias/arquivos-receitas-publicas/receitas-publicas >. Acesso em: 12 nov. 2014.

${ }^{296}$ CARRIÓ, Genaro. Notas sobre derecho y lenguaje, p. 99.

297 TORRES, Ricardo Lobo. Curso de direito financeiro e tributário, p. 186.

298 BALEEIRO, Aliomar. Uma introdução à ciência das finanças, p. 116-117. 
A relevância do presente critério será abordada no Capítulo 5, oportunidade em que tratar-se-á da dívida e do crédito público, sua natureza jurídica, mudanças de paradigmas que a conduziram à qualidade de receita ordinária e, ao final, sua relevância e influência sobre o domínio econômico. Nesse aspecto, notar-se-á, que a periodicidade com que os Estados passaram a contrair dívidas como forma de obtenção de recursos e o destino empregado foram determinantes para a mudança de paradigmas e conceitos.

\subsubsection{Receita originária e derivada}

A classificação da receita pública em originária e derivada é a mais aceita e difundida pela doutrina especializada, pois se mostra consonante com o Direito pátrio vigente.

A assertiva do parágrafo anterior é corroborada pelo fato de a Lei n. 4.320/1964, no art. $9^{\circ}$, caracterizar as receitas tributárias como derivadas e, com isso, além do econômico, adotar o critério da origem para distinguir as receitas entre aquelas provenientes do próprio setor público (originárias), e as advindas do setor privado (derivadas). É o que será abordado a seguir.

\subsubsection{Receitas originárias}

Provenientes do próprio setor público, as receitas originárias são aquelas "decorre[ntes] da exploração, pelo Estado, de seus próprios bens ou quando pode exercer sob o que se denomina de direito público disponível”299. Em suma, são geradas com a exploração do patrimônio do Estado e compreendem:

(...) as rendas provenientes dos bens e empresas comerciais ou industriais do Estado, que os explora à semelhança de particulares, sem exercer os seus poderes de autoridade, nem imprimir coercitivamente à exigência de pagamentos ou à utilização dos serviços que os justificam, embora, não raro, os institua em monopólios. A essas receitas originárias corresponderia a noção de "preços" (...). Nelas poderiam ser incluídas as receitas decorrentes da prescrição em favor do Estado, bens vacantes, heranças jacentes etc. ${ }^{300}$

Ricardo Lobo Torres ${ }^{301}$ observa que as receitas originárias agrupam duas espécies de receitas públicas: (i) os ingressos patrimoniais e (ii) os ingressos comerciais.

299 OLIVEIRA, Regis Fernandes de. Curso de direito financeiro, p. 130.

300 BALEEIRO, Aliomar. Uma introdução à ciência das finanças, p. 117.

301 TORRES, Ricardo Lobo. Curso de direito financeiro e tributário, p. 188-194. 
Os ingressos patrimoniais correspondem às rendas provenientes da exploração direta do patrimônio público e são obtidos com a exploração dos bens dominiais do Estado, como florestas, ilhas, estradas, imóveis etc.

Revestidas de variadas naturezas jurídicas - foros, laudêmios, aluguéis etc. -, suas principais formas são o preço público, as compensaçôes financeiras e as participações especiais, bem como as partilhas ${ }^{302}$.

O preço público, cujo termo é empregado como sinônimo de "tarifa" pela doutrina e pela jurisprudência, consiste na prestação pecuniária devida ao Estado a título de contraprestação pelos serviços públicos não essenciais prestados ao indivíduo ou à empresa. Detém como princípio fundamental o da proporcionalidade ou do benefício e impõe, ao cidadão que recebe o benefício do Estado, a obrigação de despender recursos idênticos ao benefício total recebido pela entrega dos serviços públicos.

Nota-se, assim, que o preço público detém caráter vinculado ou contraprestacional, pois visa remunerar o Estado pela prestação de serviços públicos não essenciais, diferenciando-se das taxas, que são receitas tributárias e, com isso, derivadas.

As compensações financeiras, por sua vez, têm fundamento jurídico constitucional no $₫ 1^{\circ}$ do art. 20, o qual assegura aos Estados, Distrito Federal, Municípios e aos órgãos da administração direta da União, participação no resultado da exploração de petróleo ou gás natural, de recursos hídricos para fins de geração de energia elétrica e de outros recursos minerais no respectivo território, plataforma continental, mar territorial ou zona econômica exclusiva, ou compensação financeira por essa exploração.

Diante disso, as compensações financeiras podem assumir (i) caráter indenizatório, o qual decorre da utilização dos recursos naturais situados no território do ente federativo e que se justifica, por conta das despesas geradas pelas empresas exploradoras desses recursos aos poderes públicos; ou (ii) caráter participativo, em que o ente público passa a perceber uma participação calculada sobre o resultado da exploração do petróleo ou gás natural ou outros bens públicos.

Quanto aos ingressos comerciais, estes têm origem na prática de formas intervencionistas do Estado na economia, mediante a instituição de monopólios (correios), criação de empresas estatais e através das loterias (concurso de prognósti$\cos )$, cujas receitas são auferidas com fundamento na distribuição de dividendos ${ }^{303}$.

302 TORRES, Ricardo Lobo. Curso de direito financeiro e tributário, p. 188.

303 RUBINSTEIN, Flávio. Orçamentos públicos: a Lei n. 4.320/1964 comentada. 2. ed. São Paulo: RT, 2010. p. 53-54. 
Assim, as receitas originárias provêm da exploração, pelo Estado, de seu próprio patrimônio, não compreendendo dentre elas as receitas resultantes da arrecadação tributária, conforme será observado a seguir.

\subsubsection{Receitas derivadas}

As receitas derivadas, por sua vez, "provêm do constrangimento sobre o patrimônio do particular" ${ }^{304}$ ou, como elucida Aliomar Baleeiro ${ }^{305}$, caracterizam-se pelo constrangimento legal para sua arrecadação, figurando dentre elas os tributos e as penas pecuniárias como as multas, por exemplo ${ }^{306}$.

Trata-se de rendas que o Estado colhe no setor privado, por ato de autoridade, e que se subdividem em: (i) impostos; (ii) taxas; (iii) contribuições de melhoria; e (iv) contribuições parafiscais, as quais, atualmente, se denominam contribuiçōes sociais ou de intervenção no domínio econômico e de interesse das categorias profissionais ou econômicas (art. 149 da CF/1988) e que, portanto, assumiram natureza jurídica tributária.

Somam-se a elas, a cobrança das sanções e o perdimento decorrente de contrabando, apreensão de armas, bens e pertences provenientes do crime etc.

A propósito, Flávio Rubinstein ${ }^{307}$ bem sintetiza ao esclarecer que:

Essas receitas configuram, portanto, meio de financiamento do Estado que não representa riqueza nova, mas mera transferência daquela que foi gerada por terceiros. Para a geração desta riqueza, não se emprega o patrimônio público, tampouco se desenvolvem atividades econômicas por parte dos entes públicos.

Além das receitas mencionadas, Regis Fernandes de Oliveira ${ }^{308}$ acrescenta uma terceira espécie ou categoria de receita derivada, a qual denomina receitas transferidas. Embora também provenham do patrimônio do particular - a título de tributo -, o que a aparta das demais é o fato de não ser arrecadada pela entidade política que vai utilizá-las (cf. arts. 157 a 162 da CF/1988).

304 OLIVEIRA, Regis Fernandes de. Curso de direito financeiro, p. 130.

305 OLIVEIRA, Regis Fernandes de. Curso de direito financeiro, p. 117.

306 De acordo com Regis Fernandes de Oliveira, a multa "é sanção de tipo pecuniário que atinge o patrimônio do transgressor de uma norma administrativa, a título de dano presumido da infração, ou de cunho meramente punitivo" (OLIVEIRA, Regis Fernandes de. Infrações e sançôes administrativas. 3. ed. revista, atualizada e ampliada, São Paulo: RT, 2012b. p. 143).

307 RUBINSTEIN, Flávio. Orçamentos públicos: a Lei n. 4.320/1964 comentada, p. 54.

308 RUBINSTEIN, Flávio. Orçamentos públicos: a Lei n. 4.320/1964 comentada, p. 130. 
Com isso, pode-se dizer, em síntese, que as receitas públicas são ordinárias ou extraordinárias de acordo com a regularidade com que são obtidas e que, quanto a sua origem, distinguem-se em receitas originárias, derivadas e transferidas, levando-se em conta o fato de provirem, respectivamente, do patrimônio do próprio Estado ou do patrimônio do particular.

\subsection{EXTRAFISCALIDADE E INTERVENÇÃO NO DOMÍNIO ECONÔMICO: ONERAÇÃO E DESONERAÇÃO}

Apresentadas as principais distinçôes e características das entradas e receitas percebidas pelo Estado, verifica-se, neste momento, que as receitas derivadas tomam salutar relevância para o objeto do presente estudo, destacando-se dentre elas o imposto como um dos principais instrumentos de intervenção no domínio econômico, ao lado do gasto público ${ }^{309}$.

Essa assertiva é corroborada por Luís S. Cabral de Moncada, quando, ao tratar do intervencionismo, bem assinala que, "No quadro das finanças contemporâneas do dirigismo o Estado pretende obter da sua actividade financeira fins de ordem socioeconómica e não apenas arrecadar receitas." ${ }^{310}$.

Além disso, em um Estado autodenominado "Estado do Imposto", cuja principal fonte de financiamento é predominantemente tributária ${ }^{311} \mathrm{e}$, portanto, proveniente de receitas derivadas, oriundas do constrangimento exercido sobre o patrimônio privado para a arrecadação de tributos ${ }^{312}$ ou, como prefere Regis Fernandes de Oliveira, de "receitas que ingressam por força da ação constritiva do Estado"313, tornar-se-ia impossível deixar de assim proceder. Afinal, como lembra o autor ${ }^{314}$,

(...) desde tempos imemoriais, os povos sempre cobraram por suas guerras de conquista. Na Roma Antiga, as colônias dominadas eram obrigadas a pagar tributos, ou seja, uma quantia calculada em pecúnia ou em bens (produtos agrícolas, gado etc.) ou em serviços (escravos que prestavam serviços abrindo estradas, limpando as propriedades etc.). Tais prestaçôes irradiaram-se através da Idade Média, apenas adquirindo contornos jurídicos e restriçôes através dos pactos de conquistas dos direitos humanos,

309 DEODATO, Alberto. As funçôes extrafiscais do imposto. 1949. Tese (Concurso de Professor Catedrático de Ciência das Finanças) - Faculdade de Direito da Universidade de Minas Gerais, Belo Horizonte, 1949. p. 64-65.

310 MONCADA, Luís S. Cabral de. Direito económico, p. 41.

311 SCHOUERI, Luís Eduardo. Normas tributárias indutoras e intervenção econômica. Rio de Janeiro: Forense, 2005. p. 1.

312 Dados disponíveis em: <http://www.camara.gov.br>. Acesso em: 14 nov. 2014.

313 OLIVEIRA, Regis Fernandes de. Curso de direito financeiro, p. 148.

314 OLIVEIRA, Regis Fernandes de. Curso de direito financeiro, p. 150. 


\section{•• O orçamento como instrumento de intervenção no domínio econômico}

tais como a Carta Magna, a "Petition of Rights", a Revolução Francesa, a Independência Americana e as Constituições que se seguiram (francesa, norte-americana, mexicana, Weimar), bem as das modernas democracias ocidentais.

A propósito, Alberto Deodato esclarece que "só quando o grupo privado passou das necessidades gerais às coletivas, foi que os homens, associados politicamente, sentiram a carência do tributo"315. Com isso, "Já não eram mais a água, o alimento, a diversão, a literatura, mas a ordem e a defesa do grupo" ${ }^{\text {"16 }}$ que tornavam necessário e imprescindível impor o constrangimento sobre o patrimônio privado.

Para que se tenha uma ideia do montante envolvido, em 2013, a estimativa da receita total da União, de acordo com a Lei n. 12.798/2013, era de R $\$$ 2.165.910.805.669,00, dos quais $\mathrm{R} \$ 956.551 .800 .557,00$ seriam provenientes do orçamento fiscal; $\mathrm{R} \$ 599.293 .304 .522,00$, do orçamento da seguridade social; e $\mathrm{R} \$$ 610.065.700.590,00, do refinanciamento da dívida fiscal.

Ao final do exercício de 2013, e de acordo com as informações disponibilizadas pela Secretaria do Tesouro Nacional, do total estimado foram arrecadados $\mathrm{R} \$$ 1.018.730.970,00, conforme se extrai do quadro a seguir (Quadro 3.1).

Quadro 3.1 Estimativa da receita total da União e receita realizada em 2013

\section{R\$ milhares}

\begin{tabular}{|l|c|c|}
\hline Especificação & Previsão de arrecadação & Receita realizada em 2013 \\
\hline Receita Tributária & 418.840 .125 & 376.042 .389 \\
\hline Receita de Contribuições & 658.606 .237 & 642.688 .581 \\
\hline Receita Patrimonial & 109.786 .992 & 85.183 .285 \\
\hline Receita Agropecuária & 23.831 & 26.494 \\
\hline Receita Industrial & 1.054 .374 & 925.163 \\
\hline Receita de Serviços & 49.105 .442 & 49.545 .002 \\
\hline Transferências Correntes & 995.931 & 732.973 \\
\hline Receitas Correntes a Classificar & 0 & 100 \\
\hline Outras Receitas Correntes & 58.055 .551 & 64.501 .823 \\
\hline TOTAL & $\mathbf{1 . 2 1 9 . 6 4 5 . 8 0 9}$ & $\mathbf{1 . 2 9 6 . 4 6 8 . 4 8 3}$ \\
\hline
\end{tabular}

Fonte: Secretaria do Tesouro Nacional. Disponível em: <http://www.tesouro.fazenda.gov.br>. Acesso em: 24 nov. 2014.

315 DEODATO, Alberto. As funçôes extrafiscais do imposto, p. 62.

316 DEODATO, Alberto. As funçôes extrafiscais do imposto, p. 62. 
Além disso, conforme já sublinhado, o Estado, desde sua instituição, sempre interveio no domínio econômico, havendo, no entanto, momentos ou períodos históricos em que essa intervenção se operava de forma ora mais branda, ora mais híspida, não se tratando, assim, e como pontua Luís S. Cabral de Moncada ${ }^{317}$, de um fenômeno historicamente permanente e idêntico em termos qualitativos e quantitativos.

A presença de regras sobre as liberdades econômicas ou a regulação da própria ordem econômica há tempos integram os ordenamentos jurídicos e as próprias Constituições de vários países, manifestando-se "em todas elas a função extrafiscal do Direito Financeiro como pressuposto para efetividade das instrumentalidades da Constituição Econômica"318.

Daí, portanto, é que se pode dizer que o orçamento público assume uma função extrafiscal, em que os tributos e, mais especificamente, os impostos, são empregados como um dos principais instrumentos de que o Estado lança mão para intervir na economia e no domínio econômico, pois são comumente utilizados para "fomentar ou mesmo corrigir, controlar e conformar o funcionamento espontâneo da decisão económica privada"319.

Com efeito, não se está aqui descobrindo nada de novo, apenas sublinhando o valor essencial do elemento teleológico na compreensão adequada do fenômeno financeiro, no que se refere à redistribuição de riquezas e a qual pode dar-se tanto com a realização de gastos quanto mediante os ingressos públicos, influenciando as condutas privadas ${ }^{320}$.

Logo, e com o propósito de demonstrar o quanto se tem afirmado nesta publicação - que o orçamento é um importante instrumento de intervenção no domínio econômico -, torna-se indispensável tratar especificamente dos tributos como fonte de receita, da fiscalidade e extrafiscalidade, para, em seguida, demonstrar sua utilização como instrumento de intervenção sobre o domínio econômico.

\subsubsection{Tributos: fiscalidade e extrafiscalidade}

Tributo, dentre suas várias acepções ${ }^{321}$, é definido no art. $3^{\circ}$ do Código Tributário Nacional (CTN) como toda prestação pecuniária compulsória, em moeda ou

\footnotetext{
317 MONCADA, Luís S. Cabral de. Direito económico, p. 41.

318 TORRES, Heleno Taveira. Teoria da constituição financeira, p. 199-200.

319 MONCADA, Luís S. Cabral de, op. cit., p. 36.

320 GONZÁLEZ, Luis Manuel Alonso. Los impuestos autonómicos de caracter extrafiscal. Madrid: Marcial Pons, 1995. p. 15.

321 CARVAlHO, Paulo de Barros. Curso de direito tributário. 13. ed. São Paulo: Saraiva, 2000. p. 19-24.
} 


\section{•• O orçamento como instrumento de intervenção no domínio econômico}

cujo valor nela se possa exprimir, que não constitua sanção de ato ilícito, instituída em lei e cobrada mediante atividade administrativa plenamente vinculada.

Rubens Gomes de Souza define tributo como sendo a

(...) receita derivada que o Estado arrecada mediante o emprego da sua soberania, nos termos fixados em lei, sem contraprestação diretamente equivalente, e cujo produto se destina ao custeio das finalidades que lhe são próprias ${ }^{322}$.

$\mathrm{O}$ conceito proposto por Geraldo Ataliba ${ }^{323}$, compartilhado também por esta dissertação, acrescenta que

tributo é a obrigação jurídica pecuniária, ex lege, que se não constitui em sanção de ato ilícito, cujo sujeito ativo é uma pessoa pública (ou delegado por lei desta), e cujo sujeito passivo é alguém nessa situação posto pela vontade da lei, obedecidos os desígnios constitucionais (explícitos ou implícitos).

Como salienta Regis Fernandes de Oliveira ${ }^{324}$ ao decompor a definição proposta por Geraldo Ataliba, "o tributo não é o pagamento, mas a obrigação de entregar dinheiro (pecuniária) aos cofres públicos”.

$\mathrm{Na}$ contramão do pensamento de boa parte da doutrina ${ }^{325}$ e, portanto, do entendimento de que a obrigação tributária detém caráter pecuniário, ou seja, deve ser satisfeita em dinheiro, Alfredo Augusto Becker defende posição segundo a qual "o tributo, no plano material, não precisa ser dinheiro, pode perfeitamente consistir numa coisa (prestação in natura) ou num serviço (prestação in labore)"326.

A fim de justificar seu posicionamento, Alfredo Augusto Becker ${ }^{327}$ argumenta:

O dever jurídico de prestação em dinheiro é dever de dar determinada quantidade de unidade ideal de valor conduzida (ou incorporada) pelo dinheiro. Por sua vez, este dever jurídico de prestação em dinheiro pode não ser originário, mas derivado da transformação de um dever, originariamente, in natura ou in labore; transformação sugerida pela função econômica do dinheiro que pode servir de substitutivo de toda e qualquer prestação de outra natureza.

322 SOUZA, Rubens Gomes de. Compêndio de legislação tributária. Coord. IBET - Instituto Brasileiro de Estudos Tributários; obra póstuma. São Paulo: Resenha Tributária, 1975. p. 39.

323 ATALIBA, Geraldo. Hipótese de incidência tributária. 6. ed. São Paulo: Malheiros, 2000. p. 34.

324 OLIVEIRA, Regis Fernandes de. Curso de direito financeiro, p. 150.

325 Dentre os que não são adeptos à teoria defendida por Alfredo Augusto Becker, figuram: JÈZE, Gaston. Principios generales del derecho administrativo, v. II, t. I, p. 252; INGROSSO, Giovanni. Diritto finanziario, p. 98; FALCÃO, Amílcar de Araújo. Introdução ao direito tributário. Rio de Janeiro: Ed. Financeiras, 1955. p. 34-36.

326 BECKER, Alfredo Augusto. Teoria geral do direito tributário. 3. ed. São Paulo: Lejus, 2002. p. 286.

327 BECKER, Alfredo Augusto. Teoria geral do direito tributário p. 633. 
Portanto, a fim de que a relação jurídica tenha natureza jurídica tributária, pouco importa que a obrigação, por ela gerada, seja satisfeita por uma prestação em dinheiro ou in natura ou in labore, pois, nas três hipóteses, o conteúdo jurídico da prestação será sempre o mesmo: um prestar, isto é, um ato positivo (facere) ou um ato negativo (non facere) do sujeito passivo na relação jurídica. Por sua vez, o sujeito ativo, no outro polo da relação jurídica, terá, nas três hipóteses, sempre o mesmo direito de natureza pessoal.

Embora se mostre adequada a posição externada por Alfredo Augusto Becker, a ideia de que a obrigação jurídica tributária, consistente em pagar tributo, deve se realizar mediante a entrega de dinheiro aos cofres públicos se coaduna com o pensamento defendido nesta dissertação, valendo assinalar que as obrigações jurídicas aludidas "independem da vontade do sujeito passivo, que deve efetivá-la, ainda que contra seu interesse" 328 .

É daí, consequentemente, que advém a denominação das receitas derivadas, ou seja, como são identificados os valores que integram o caixa da entidade pública que provêm do constrangimento sobre o patrimônio do particular ${ }^{329}$ e cuja "finalidade última almejada pela lei, no caso, é a transferência de dinheiro das pessoas privadas, submetidas ao poder do Estado, para os cofres públicos"330.

Em suma, o tributo constitui uma espécie de receita e um instituto próprio do direito financeiro, cuja definição e instituição, sob o ponto de vista jurídico, a ele está atrelado e não ao direito tributário ${ }^{331}$ como se presumiria ${ }^{332}$. Não por menos, Fernando Pérez Royo ${ }^{33}$ assinala, ao conceituar tributo, o fato de a lei vincular o dever de contribuir, com o propósito de obter recursos necessários para sustentar os gastos públicos.

Daí a exigência e nascimento dos tributos, os quais devem ser instituídos por lei e de acordo com o texto constitucional, conforme reza o inc. II do art. $5^{\circ}$, da Constituição Federal, ao estabelecer que "ninguém será obrigado a fazer ou deixar

328 CARVALHO, Paulo de Barros. Curso de direito tributário, p. 25.

329 OLIVEIRA, Regis Fernandes de. Curso de direito financeiro, p. 130.

330 ATALIBA, Geraldo. Hipótese de incidência tributária, p. 29.

331 SOUZA, Rubens Gomes de. Compêndio de legislação tributária, p. 39.

332 Conforme Geraldo Ataliba assinala, "o conceito de tributo para o direito é um conceito jurídico privativo, que se não pode confundir com o conceito financeiro, ou econômico de outro objeto, de outros setores científicos, como é o tributo ontologicamente considerado. Tributo, para o direito, é coisa diversa de tributo como conceito de outras ciências" (ATALIBA, Geraldo. Hipótese de incidência tributária, p. 23).

333 ROYO, Fernando Pérez. Derecho financiero y tributario: parte general. 20. ed. Sevilla: Thomson Reuters, 2010. p. 38. 


\section{•• O orçamento como instrumento de intervenção no domínio econômico}

de fazer alguma coisa senão em virtude de lei”, e o inc. I do art. 150, quando veda aos entes tributantes, detentores da prerrogativa de instituir e arrecadar tributos, que exijam ou aumentem tributo sem lei que o estabeleça.

A história tem mostrado a necessidade de se impor limites à liberdade de tributar conferida ao Estado, pois, como afirmou John Marshall, Chief of Justice da Corte dos Estados Unidos da América, no caso McCulloch v. Maryland, de 1819, quando o Estado de Maryland insistia em cobrar impostos do Second Bank of the United States, "o poder de tributar envolve o poder de destruir".

Embora o contribuinte, devedor de qualquer espécie de tributo, não possa questionar sua aplicação - se o gasto está sendo ou não realizado em seu proveito -, pode exigir que sua imposição se dê em consonância com as regras jurídicas de competência, de acordo com o princípio da isonomia, e que sua inserção seja devidamente lançada na peça orçamentária ${ }^{334}$.

Ademais, como Regis Fernandes de Oliveira ${ }^{335}$ assevera:

O tributo não pode constituir-se em sanção de ato ilícito. Para este existe a multa, ou seja, a prática de ato ilícito pressupõe o descumprimento de uma norma jurídica, isto é, ter um comportamento contrário ao previsto na lei. Nesta hipótese, a reação do ordenamento jurídico ocorre através de uma sanção. Se a repulsa ao comportamento antijurídico é a sanção, não há possibilidade de, em razão dele, exigir-se um tributo.

Desponta, com isso, uma das principais atribuiçōes ou finalidades do tributo: a fiscalidade, ou seja, "o comportamento do Poder Público com o único intuito de abastecimento dos cofres públicos. É o poder de instituição de tributos, desprovido de qualquer finalidade que não a arrecadatória"336.

O termo fiscalidade, como assinala Paulo de Barros Carvalho ${ }^{337}$, é empregado "para representar valores finalísticos que o legislador imprime na lei tributária", verificado

(...) sempre que a organização jurídica do tributo denuncie que os objetivos que presidiram sua instituição, ou que governam certos aspectos da sua estrutura, estejam voltados ao fim exclusivo de abastecer os cofres públicos, sem que outros interesses - sociais, políticos ou econômicos - interfiram no direcionamento da atividade impositiva ${ }^{338}$.

334 BECKER, Alfredo Augusto. Teoria geral do direito tributário, p. 289.

335 BECKER, Alfredo Augusto. Teoria geral do direito tributário, p. 150.

336 OLIVEIRA, Regis Fernandes de. Curso de direito financeiro, p. 162.

337 OLIVEIRA, Regis Fernandes de. Curso de direito financeiro, p. 228.

338 OLIVEIRA, Regis Fernandes de. Curso de direito financeiro, p. 228. 
Todavia, na hipótese de se agregar ao propósito meramente arrecadatório da fiscalidade a intenção de conformar comportamentos, ter-se-á o que se denomina por extrafiscalidade, a qual, também de acordo com Paulo de Barros Carvalho, consiste na "forma de manejar elementos jurídicos usados na configuração dos tributos, perseguindo objetivos alheios aos meramente arrecadatórios"339.

Os objetivos citados, como diz o autor, podem ser traduzidos em providências tendentes a prestigiar certas situaçôes sociais, políticas ou econômicas, às quais o legislador dispensa tratamento mais confortável ou menos gravoso ${ }^{340}$, bem como se prestam a desestimular comportamentos contrários a situaçôes socialmente indesejáveis ${ }^{341}$, podendo-se, com isso, afirmar:

La pura fiscalidad no existe, así como tampoco la extrafiscalidad pura. Los efectos de los tributos no son identificables por separado y, en alguna medida, coexisten funciones recaudatorias y reguladoras con distinta intensidad conforme a la naturaleza propia de cada tributo ${ }^{342}$.

Em alguns tributos, especialmente nos chamados impostos indiretos ${ }^{343}$, os quais incidem sobre situação instantânea e são suportados por terceiros ${ }^{344}$ - por exemplo, Imposto sobre Operações Relativas à Circulação de Mercadorias e sobre Prestação de Serviços de Transporte Interestadual e Intermunicipal e de Comunicação (ICMS), Imposto sobre Produtos Industrializados (IPI) e Contribuição para o Financiamento da Seguridade Social (Cofins) - essas características se afloram e, não obstante a evidente função fiscal, é possível afirmar que são utilizados como instrumentos intervencionistas, ainda que mediatamente não se possa excluir o princípio da capacidade contributiva ${ }^{345}$.

Mostra-se importante, neste momento, tratar dos objetivos da extrafiscalidade, os quais foram sintetizados com precisão por Aliomar Baleeiro ${ }^{346}$, nos seguintes termos:

339 OLIVEIRA, Regis Fernandes de. Curso de direito financeiro, p. 229.

340 OLIVEIRA, Regis Fernandes de. Curso de direito financeiro, p. 228-229.

341 OLIVEIRA, Regis Fernandes de. Curso de direito financeiro, p. 162.

342 ROSEMBUJ, Tulio. Elementos de derecho tributario. In: GONZÁLEZ, Luis Manuel Alonso. Los impuestos autonómicos de caracter extrafiscal, p. 21.

343 De acordo com Geraldo Ataliba, "É classificação que nada tem de jurídica; seu critério é puramente econômico. Foi elaborada pela ciência das finanças, a partir da observação do fenômeno econômico da translação ou repercussão dos tributos" (ATALIBA, Geraldo. Hipótese de incidência, p. 143).

344 OLIVEIRA, Regis Fernandes de. Curso de direito financeiro, p. 165.

345 TORRES, Heleno Taveira. Teoria da constituição financeira, p. 227.

346 BALEEIRO, Aliomar. Uma introdução à ciência das finanças, p. 176. 
Quando os impostos são empregados como instrumento de intervenção ou regulação pública, a função fiscal propriamente dita, ou "puramente fiscal”, é sobrepujada pelas funções "extrafiscais". A sua técnica é, então, adaptada ao desenvolvimento de determinada política, ou diretriz.

Com efeito, os tributos não se prestam apenas a abastecer os cofres do Estado para que este possa atender às necessidades pactuadas solenemente. Além dessa função, e de modo geral, também servem à promoção e desenvolvimento do domínio econômico, à regularização e fiscalização da economia e, com isso, assumem verdadeiro caráter interventivo, seja para restringir a prática de determinados atos ou comportamentos, seja para fomentar e até mesmo induzir a iniciativa privada a fazer ou deixar de fazer algo.

\subsubsection{A extrafiscalidade como instrumento de intervenção}

Diante do proposto inicialmente, faz-se pertinente, mais uma vez, esclarecer que não se tem como propósito abordar as espécies de tributo e sua classificação, tampouco os aspectos da hipótese de incidência tributária ${ }^{347}$. O objeto de análise limitar-se-á, neste tópico, a demonstrar de que forma os tributos são utilizados como instrumento de intervenção sobre o domínio econômico, bem como sua relevância e eventuais reflexos.

Daí por diante, e partindo do pressuposto que todos os tributos de uma forma ou de outra exercem certa função extrafiscal ${ }^{348}$, pois há séculos são percebidos os efeitos da tributação sobre redistribuição do capital e da renda entre os indivíduos e sobre a formação das classes sociais ${ }^{349}$, pode-se dizer que a extrafiscalidade

(...) é sempre uma tributação com fim "fiscal" (competência tributária) à qual são atrelados "motivos constitucionais" materiais de outras competências (da Constituição Econômica ou da Constituição Social, por exemplo), como concretização dos fins constitucionais do Estado, na forma e condiçōes autorizadas pela própria Constituição ${ }^{350}$.

A propósito, Alfredo Augusto Becker ${ }^{351}$ já assinalava que a extrafiscalidade assumiria a posição de principal finalidade de muitos tributos, sobrepondo-se, com

347 Para aprofundamento sobre o tema, remete-se às lições de OLIVEIRA, Regis Fernandes de.

Curso de direito financeiro, p. 164-179.

348 TORRES, Heleno Taveira. Teoria da constituição financeira, p. 229.

349 BALEEIRO, Aliomar. Uma introdução à ciência das finanças, p. 179.

350 TORRES, Heleno Taveira, op. cit., p. 229.

351 BECKER, Alfredo Augusto. Teoria geral do direito tributário, p. 269. 
isso, a arrecadação de recursos para o custeio das despesas públicas e, consequentemente, consistiria em importante instrumento de intervenção estatal no meio social e na economia privada.

Com o intuito de demonstrar o quanto afirmam os autores em comento, mostra-se pertinente citar alguns dos exemplos propostos por Aliomar Baleeiro ${ }^{352}$, os quais demonstrarão que a extrafiscalidade atua sobre o domínio econômico com a finalidade de prestigiar certas situações sociais, políticas ou econômicas. Vejam-se:

(i) majoração dos impostos sobre importação (II), circulação de bens e mercadorias (ICMS) e sobre produtos industrializados (IPI), como instrumento de proteção à produção nacional, agrícola ou fabril ou de combate ao luxo;

(ii) redução ou desoneração de impostos com o propósito de promover o amparo à saúde pública e à higiene alimentar;

(iii) "fragmentação dos latifúndios ou remembramento de minifúndios e punição do ausentismo por impostos progressivos sobre a área desocupada ou sobre heranças recebidas por pessoas residentes fora da jurisdição do governo, que exerce o poder de tributar";

(iv) incentivos por isenções à instalação de indústrias novas;

(v) estímulos à construção e ao aproveitamento de áreas urbanas desocupadas, degradadas etc.;

(vi) restabelecimento da propensão ao consumo, como política fiscal em que se institua mais impostos progressivos sobre a herança e a renda; etc.

Além desses, merece destaque a citada utilização da extrafiscalidade como "política fiscal para manutenção do equilíbrio econômico pelo controle das tendências à flutuação ou de estímulo ao desenvolvimento econômico, sobretudo nos países novos" 353 , pois intimamente atrelado aos objetivos propostos inicialmente neste estudo, em que se busca demonstrar que o orçamento constitui importante instrumento de intervenção no domínio econômico, sendo merecedor de maior atenção e responsabilidade daqueles que o elaboram e executam.

Como Aliomar Baleeiro adverte, "para obtenção de qualquer dos fins acima expostos, existe problema de prognósticos de efeitos econômicos e de escolha de técnica adequada" 354 , cabendo, assim, ao legislador e ao Poder Executivo, ponderar os efeitos econômicos das medidas que adotam desde a elaboração da peça orçamentária.

352 BALEEIRO, Aliomar. Uma introdução à ciência das finanças, p. 178-179.

353 BALEEIRO, Aliomar. Uma introdução à ciência das finanças, p. 179.

354 BALEEIRO, Aliomar. Uma introdução à ciência das finanças, p. 179. 
Por constituir o orçamento "a lei periódica que contém previsão de receitas e fixação de despesas, programando a vida econômica e financeira do Estado, de cumprimento obrigatório, vinculativa do comportamento do agente público"355, sua elaboração, conforme se observou, não deveria jamais dar-se sem qualquer planejamento, o qual, como também já salientado, consiste em uma "forma de ação racional caracterizada pela previsão de comportamentos econômicos e sociais futuros, pela formulação explícita de objetivos e pela definição de meios de ação coordenadamente dispostos" 356 .

Por isso caracteriza-se a extrafiscalidade pelo "emprego deliberado do instrumento tributário para finalidades (...) regulatórias de comportamentos sociais, em matéria econômica, social e política"357, e, como propõe Luís Eduardo Schoueri ${ }^{358}$, tratar-se-ia de "normas tributárias indutoras como espécie do gênero extrafiscalidade".

Tanto é assim que essas questôes foram objeto de preocupação do constituinte originário nos arts. $150, \$ 6^{\circ}, 155, \$ 2^{\circ}$, inc. XII, alínea $g$, e $165, \$ 6^{\circ}$, e do constituinte derivado, por ocasião da edição da Emenda Constitucional n. 42/2003, a qual acrescentou ao texto constitucional o art. 146-A, ao dispor que cabe à lei complementar "estabelecer critérios especiais de tributação, com o objetivo de prevenir desequilíbrios da concorrência".

A despeito das diversas modalidades de intervenção já abordadas, a extrafiscalidade, a qual detém dentre uma de suas espécies as normas tributárias indutoras, de acordo com Luís Eduardo Schoueri, constitui um modo de intervenção por indução no domínio econômico, o qual se dá por meio da criação e instituição de estímulos ou desincentivos do Estado. Nas palavras do referido autor ${ }^{359}$, a

(...) indução por estímulos, proporciona o Estado, vantagens adicionais àqueles que incorrem nos atos contemplados pela norma, que não seriam obtidas no livre funcionamento do mercado; no caso de desincentivos, recai o destinatário da norma em custos que não lhe seriam imputados, em caso de livre curso do mercado.

Luís Eduardo Schoueri salienta ainda que, longe de constituir uma exceção, as normas tributárias indutoras surgem em obediência ao preceito constitucional da atuação positiva do Estado, tornando-se um potente instrumento para atuação

355 OLIVEIRA, Regis Fernandes de. Curso de direito financeiro, p. 366.

356 GRAU, Eros Roberto. A ordem econômica na Constituição de 1988, p. 150.

357 ATALIBA, Geraldo. Sistema constitucional tributário brasileiro. São Paulo: RT, 1968. p. 150-151.

358 SCHOUERI, Luís Eduardo. Normas tributárias indutoras e intervenção econômica, p. 32-34.

359 SCHOUERI, Luís Eduardo. Normas tributárias indutoras e intervenção econômica, p. 54. 
em determinado sentido político, seja na escolha dos sujeitos que devem suportar os ônus devidos por dado programa de despesas, seja na escolha dos fatos cuja concretização faz nascer a obrigação tributária ${ }^{360}$.

Justificada está, em razão disso, a adoção de determinadas medidas indutoras ou de incentivo, como a isenção, a subvenção e até mesmo a renúncia de receita, que tem como um de seus principais objetivos beneficiar a sociedade e, por consequência, o domínio econômico e que, de acordo com Ricardo Lobo Torres ${ }^{361}$, tratar-se-ia de privilégios, ou seja, uma

(...) permissão para fazer ou deixar de fazer alguma coisa contrária ao direito comum. Pode ser negativo, como o privilégio fiscal consistente nas isenções e reduções de tributos, que implicam sempre uma concessão contrária à lei. Pode ser positivo, como o privilégio financeiro representado pelos incentivos, subvenções, subsídios e restituições de tributo, que consubstanciam a concessão de tratamento preferencial.

Neste aspecto, é válido lembrar que o art. 14 da LRF ${ }^{362}$ impóe à concessão ou ampliação de incentivos ou benefícios de natureza tributária decorrente de renúncia

360 SCHOUERI, Luís Eduardo. Normas tributárias indutoras e intervenção econômica, p. 87.

361 TORRES, Ricardo Lobo. Tratado de direito constitucional, financeiro e tributário: o orçamento na Constituição, p. 261.

362 Veja-se: "Art. 14. A concessão ou ampliação de incentivo ou benefício de natureza tributária da qual decorra renúncia de receita deverá estar acompanhada de estimativa do impacto orçamentário-financeiro no exercício em que deva iniciar sua vigência e nos dois seguintes, atender ao disposto na lei de diretrizes orçamentárias e a pelo menos uma das seguintes condições:

I - demonstração pelo proponente de que a renúncia foi considerada na estimativa de receita da lei orçamentária, na forma do art. 12, e de que não afetará as metas de resultados fiscais previstas no anexo próprio da lei de diretrizes orçamentárias;

II - estar acompanhada de medidas de compensação, no período mencionado no caput, por meio do aumento de receita, proveniente da elevação de alíquotas, ampliação da base de cálculo, majoração ou criação de tributo ou contribuição.

$\$ 1^{\circ}$ A renúncia compreende anistia, remissão, subsídio, crédito presumido, concessão de isenção em caráter não geral, alteração de alíquota ou modificação de base de cálculo que implique redução discriminada de tributos ou contribuições, e outros benefícios que correspondam a tratamento diferenciado.

$\$ 2^{\circ}$ Se o ato de concessão ou ampliação do incentivo ou benefício de que trata o caput deste artigo decorrer da condição contida no inciso II, o benefício só entrará em vigor quando implementadas as medidas referidas no mencionado inciso.

$\$ 3^{\circ} \mathrm{O}$ disposto neste artigo não se aplica:

I - às alterações das alíquotas dos impostos previstos nos incisos I, II, IV e V do art. 153 da Constituição, na forma do seu $₫ 1^{\circ}$;

II - ao cancelamento de débito cujo montante seja inferior ao dos respectivos custos de cobrança." 


\section{•• O orçamento como instrumento de intervenção no domínio econômico}

de receita a adoção "de certas medidas de cautela fiscal para que seja considerada legal"363.

A propósito, Eros Roberto Grau ${ }^{364}$, com supedâneo em escritos de outros doutrinadores, sintetiza e esclarece que:

A ordem econômica na Constituição de 1988 contempla a economia de mercado, distanciada porém do modelo liberal puro e ajustada à ideologia neoliberal (Washington Peluso Albino de Souza); a Constituição repudia o dirigismo, porém acolhe o intervencionismo econômico, que não se faz contra o mercado, mas a seu favor (Tércio Sampaio Ferraz Júnior); a Constituição é capitalista, mas a liberdade apenas é admitida enquanto exercida no interesse da justiça social e confere prioridade aos valores do trabalho humano sobre todos os demais valores da economia e mercado (José Afonso da Silva).

É o que também se extrai do já citado art. 174 da Constituição Federal, o qual atribui ao Estado, dentre outras, a função de incentivar o setor privado, facilmente percebido quando este se vale da extrafiscalidade para intervir sobre o domínio econômico.

Para tanto, basta verificar que os Estados comumente recorrem aos tributos para: (i) simplificar ou diminuir os custos da administração; (ii) promover a equidade; (iii) corrigir desvios do mercado econômico; (iv) promover a equalização de rendas entre regiōes; (v) promover ou incentivar determinados setores da economia com a concessão de subvenções, como adiante demonstrado etc.

Alberto Deodato bem pontua que "o imposto não é somente um meio de cobrir as necessidades financeiras, mas um meio de cobertura que intervém, também, para corrigir a repartição das rendas e da fortuna que se opera sob o império da livre concorrência"365.

O patrimônio dos particulares que pretendem usufruir desses benefícios condicionados é diretamente afetado, uma vez que, diante da promessa de serem beneficiados, também podem ser induzidos a realizar investimentos e, com isso, despender recursos a fim de atender às respectivas condiçōes de concessão desses benefícios $^{366}$.

363 RUBINSTEIN, Flávio. Boa-fé objetiva no direito financeiro e no direito tributário brasileiros. 2008. 213 f. Dissertação (Mestrado) - Universidade de São Paulo, São Paulo, 2008, p. 139.

364 GRAU, Eros Roberto. A ordem econômica na constituição de 1988, p. 191-192.

365 DEODATO, Alberto. As funçôes extrafiscais do imposto, p. 27.

366 RUBINSTEIN, Flávio. Boa-fé objetiva no direito financeiro e no direito tributário brasileiros, p. 139. 
Benvenuto Griziotti ${ }^{367}$ segue esse raciocínio ao afirmar que:

El impuesto puede inducir a los contribuyentes a aumentar la producción o perfeccionar sus métodos (por ejemplo: con reducción de derroches de mano de obra o de subproductos o con el empleo de máquinas modernas) para alejar o remover (de ahí el término de remoción del impuesto) la carga tributaria. Con la mayor producción aumenta la oferta y disminuyen los precios, con sucesivas influencias sobre la economía de los empresarios y de los consumidores.

Em razão disso, não há como afastar o fato de que os tributos, como receitas orçamentárias que são, exercem fundamental papel de intervenção sobre o domínio econômico, conformando e orientando-o.

Acabam por impor ou, no mínimo, induzir a iniciativa privada - o contribuinte - a adotar determinada conduta ou medida que pode redundar em significativo efeito para o Estado e para a sociedade como um todo.

Como assinala Armando Giorgetti ${ }^{368}$, o sujeito passivo da obrigação tributária, diante do dever de pagar determinado imposto, reagirá de forma diversa de outros e de acordo com seus impulsos e das circunstâncias de tempo e lugar.

Além disso, e de acordo com as razões individuais de cada contribuinte, as quais podem ser "legítimas" ou "ilegítimas", diferentes efeitos de ordem econômica poderão ser sentidos ${ }^{369}$. Os impactos negativos ou positivos poderão refletir na distribuição de lucros, nos níveis de investimentos e até mesmo nos salários, influindo, consequentemente, no aumento ou diminuição da economia.

Nessa linha de pensamento é a lição de Aliomar Baleeiro ${ }^{370}$, para quem

Os tributos provocam diferentes reações econômicas e psicológicas dos contribuintes. Poderão estimular o pleno emprego e até o inconveniente hiper-emprego. Poderão também ativar a preferência pela liquidez, através da oferta maciça de mercadorias para realizar disponibilidades de dinheiro em caixa, suscitando baixa de preços e até a depressão.

Por fim, e levando em conta que o propósito perseguido pelo Estado é a promoção da justiça social e não intervir no domínio econômico, mas fiscalizando e incentivando a atividade privada, a extrafiscalidade assume o papel de importante instrumento de promoção da justiça social.

367 GRIZIOTTI, Benvenuto. Principios de ciencia de las finanzas. 6. ed. Buenos Aires: Depalma. 1959. p. 97.

368 GIORGETTI, Armando. Lezioni di scienza delle finanze e di diritto finanziario. Padova: Dott. Antonio Milani, 1972. p. 50-51.

369 GIORGETTI, Armando. Lezioni di scienza delle finanze e di diritto finanziario, p. 51.

370 BALEEIRO, Aliomar. Uma introdução à ciência das finanças, p. 152. 
Mostra-se oportuno, assim, citar as três medidas exemplificativas enumeradas por Héctor Belisario Villegas ${ }^{371}$, segundo o qual:

1) Pueden producirse medidas disuasivas con respecto a actividades que no se consideran convenientes, por lo cual se procede a desalentarlas mediante medios financieros, como es el incremento de alícuotas en los tributos, la creación de sobretasas, adicionales o recargos.

2) Per el contrario, el Estado puede decidir realizar acciones alentadoras para atraer ciertas actividades económicas, científicas, culturales o de otro tipo, que estime necesarias y útiles para el país. En tal caso, despliega una serie de medidas que pueden consistir en exenciones de tributos, diferimientos, deducciones, reintegros, etcétera.

3) También se desarrolla finalidad extrafiscal por medios financieros cuando se resuelve percibir tributos de alto monto para debilitar ciertas posiciones patrimoniales y redituarias de los sujetos que se desea alcanzar, como manera de modificar la estructura en la distribución de los patrimonios y las rentas

De outra sorte, nem sempre a indução manifesta-se em termos positivos. $\mathrm{O}$ Estado, quando onera o contribuinte criando ou elevando determinado imposto, tal como no caso de importação de determinados bens, busca restringir ou evitar esse comportamento, podendo-se dizer que a indução é negativa ${ }^{372}$.

A norma, ainda que não proíba a importação desses bens, onera-a de tal modo que a torna economicamente proibitiva.

De fato, há impostos cuja finalidade não é render, como se verifica "quando se estabelece um imposto contra o luxo ou contra o álcool; quando se cria uma tarifa alta para certas mercadorias importadas; quando se diminui o imposto sobre as novas construçôes" ${ }^{\prime 373}$. O Estado opta por afastar os efeitos do não rendimento, anulando a ostentação do luxo inútil, eliminando ou aliviando a chaga social do alcoolismo e, "sendo nula a importação de certas mercadorias estrangeiras, florescem as indústrias nacionais similares, enriquecendo a economia" ${ }^{374}$.

O Estado se apropria da extrafiscalidade como instrumento versátil e intercambiário para esquematizar e simplificar sua utilização como mecanismo de promoção, incentivo e estímulo ao setor privado, ou, em sentido contrário, como instrumento de limitação, freio, desincentivo e até mesmo sanção $0^{375}$.

371 VILLEGAS, Héctor Belisario. Curso de finanzas, derecho financiero y tributario. 9. ed. Buenos Aires: Depalma, 2007. p. 15.

372 GRAU, Eros Roberto. A ordem econômica na Constituição de 1988, p. 149.

373 DEODATO, Alberto. As funçôes extrafiscais do imposto, p. 64-65.

374 DEODATO, Alberto. As funçôes extrafiscais do imposto, p. 65.

375 GONZÁLEZ, Luis Manuel Alonso. Los impuestos autonómicos de caracter extrafiscal, p. 47. 
Esses mecanismos, além de terem de ser utilizados de acordo com os limites e ditames legais, são facilmente identificados no sistema jurídico brasileiro por meio da isenção, remissão, alteração da base de cálculo ou alíquota de determinado tributo, do diferimento e, até mesmo, da renúncia de receita, para provocar os efeitos desejados na economia e na sociedade.

Pari passu, as previsões orçamentárias apontadas geram expectativas naqueles que delas poderão se valer direta e indiretamente e, "quando frustradas, poderão levar à violação do princípio da boa-fé objetiva” ${ }^{376}$.

Não apenas os tributos, mas as finanças como um todo, e cada vez mais, têm se revelado poderoso instrumento nas mãos dos governos para a consecução de fins de caráter econômico, político e social, sendo difícil fixar limites que sejam capazes de apontar onde acaba a finalidade fiscal e onde começam os fins político-econômicos.

É o que se notará, também, ao tratar do gasto público e da dívida pública, pois, na hipótese de se levar em conta que todo o orçamento é um ato político, também será preciso considerar o fato de que todos os atos praticados pelos governantes são motivados por razões ideológicas, por dominação e movidos por interesses pessoais, os quais, evidentemente, não se reduzem a atos de maldade ou vingança.

376 RUBINSTEIN, Flávio. Boa-fé objetiva no direito financeiro e no direito tributário brasileiros, p. 137. 
